\title{
ARTIGO
}

\section{A interferência do português na construção de orações existenciais em língua inglesa (LE)}

Karolina da Conceição Morais

Universidade de Brasília

\section{RESUMO}

O presente artigo pretende comparar as estruturas de construções existenciais nas línguas inglesa e portuguesa, demonstrando que os alunos, por influência da língua materna (português), se utilizam do verbo "have" para formular sentenças em tal estrutura, tanto na fala quanto na escrita, na língua inglesa. A partir dessa observação, percebe-se que o falante faz interferência de uma estrutura da língua materna (já que ele utiliza o verbo "ter" para denominar existência) para língua que está sendo adquirida, nesse caso, o inglês, resultando na fossilização dessa estrutura.

Palavras-chave: construções existenciais, língua materna, verbo "have", "there + to be", fossilização.

\section{Introdução}

No presente artigo, pretende-se mostrar o resultado de uma pesquisa a respeito das orações existenciais em inglês, as quais acabam sendo utilizadas erroneamente pelos alunos que estão aprendendo inglês como língua estrangeira ( $L E)$, levando ao uso de "have" no lugar de "there to be",tornando-se assim um erro fossilizado na fala de muitos desses alunos que participaram dessa pesquisa.

Antes de iniciar a leitura, é importante distinguir bem o que é língua materna (LM) e o que é língua estrangeira (LE). Segundo Coracini (2007), a língua materna não é só aquela língua na qual o indivíduo foi alfabetizado, mas ela é também a língua "do desejo, do conforto e do bem estar". Ela é a língua que adquirimos de maneira espontânea a partir do momento em que nascemos. Para Almeida Filho (2007, p. 64), uma língua materna "é uma língua que se presta à comunicação ampla desde a casa, passando pela rua até a escola e os meios culturais. Ela é uma língua em que se constitui a identidade pessoal, regional, étnica e cultural da pessoa" e a língua estrangeira, Filho (2007) diz que 
é "língua não materna que se sobrepõe a outra(s) que circula(m) setorialmente ou com restrições. É qualquer língua apreendida pela pessoa que não seja a sua primeira língua e que será aprendida por vários motivos".

Sabendo disso, dividiu-se este artigo em quatro seções: A primeira delas diz respeito a uma parte mais linguística e histórica, faz-se uma busca histórica das orações existenciais e, posteriormente, fala-se um pouco da estrutura das orações existenciais no português e inglês. A seção dois traz conceitos importantes acerca da ideia de erro na aprendizagem de uma língua estrangeira. A terceira seção é sobre a metodologia utilizada para a pesquisa e tudo e todos que estiveram envolvidos na mesma e, por último, há análise dos dados coletados juntamente com o resultado da pesquisa.

\section{Sobre a história e estrutura das construções existenciais}

Nesta seção, fala-se sobre como as construções existenciais são formadas no português e inglês e suas peculiaridades. Aqui também é feito um breve histórico da língua portuguesa e como a estrutura existencial chegou ao que temos nos dias de hoje, bem como, passa-se brevemente pela história da língua inglesa com exemplo de oração existencial em inglês médio.

\subsection{Um pouco de história}

As construções existenciais têm sido objeto de pesquisa de muitos pesquisadores, de forma sincrônica e diacrônica. Esses estudos têm focado na relação entre os verbos que formam construções possessivas e existenciais, uma vez que alguns teóricos defendem que essas construções possuem uma mesma estrutura subentendida. Há pesquisas sobre a língua portuguesa que abordam o trajeto dos verbos ser, estar, haver e ter na história, apresentando a ligação que eles têm quando se substitui um pelo outro em determinadas sentenças.

Os verbos ser, estar, haver e ter podem ser trocados entre si na execução de diferentes funções, tais como a de auxiliares, possessivos e existenciais. De acordo com Mattos e Silva (1995), nos séculos IV e V, as formas seer e habēre já se encontravam em variação nas construções existenciais no latim vulgar (representadas pelo verbo esse no latim clássico), enquanto habēre estava em variação com tenere em construções possessivas. No latim clássico, o verbo habere significava possuir, obter, manter, reter, segurar, conter, deter, entre outros, e, gradualmente, aver, no latim vulgar foi perdendo o significado original e o verbo teer foi dominando o significado acima, o qual mais tarde se restringiu somente ao sentido de possuir. A partir disso, observa-se que essas mudanças não começaram no português, mas trata-se de algo que vem do latim.

Ainda de acordo com Mattos e Silva (1995), no século XV, já era preferido usar haver existencial ao invés de ser-existencial e o ter possessivo já sobressai ao haver possessivo em todos os contextos no século XVI. Ainda nesse século, há registro de um contexto em que ter aceita a interpretação de posse e de existência: 
[...] se metiam [eles] em almaadias duas ou três que hy tiinhan [...] (MATTOS E SILVA, 1996:187)

Ribeiro (1996) afirma que o uso de aver, nas existenciais, inicia-se no português arcaico, já que no latim clássico as existenciais eram formadas com o verbo esse. $O$ autor traz também exemplos retirados de Os Luisíadas em que os verbos ter, haver e ser são usados em sentenças existenciais, Ribeiro (1996:373):

a. ........ e assim caminha Para a povoação, que perto tinha (Lus. V, 29)

b. Que aqui gente de Cristo não havia (Lus. I, 102)

c. Um Rei, por nome Afonso, foi na Espanha (Lus. III, 23)

Ele acrescenta que o verbo ser se realizava ao lado de estar em orações locativas no português arcaico e, mais tarde, estar prevaleceu nesse tipo de construção. Dessa forma, ser era utilizado nas perifrásticas passivas e ativas, e nas construções existenciais e locativas. Hoje em dia, no português do Brasil, mantém o uso nas orações passivas.

Já o inglês, esse foi influenciado pela cultura de vários povos, Le Breton (2005) afirma que "de modo semelhante à maioria das línguas europeias modernas, talvez até mais que as outras, o inglês é uma língua compósita, que reúne contribuições celtas, latinas, francesas, germânicas, para falar exclusivamente das principais". A partir dessa afirmação, infere-se que o inglês tem heranças culturais e linguísticas não só para formação da língua, mas também dos costumes dos falantes da mesma.

A língua inglesa foi marcada por três períodos durante seu processo de evolução, são eles: OldEnglish (Inglês antigo); MiddleEnglish(Inglês Médio) e ModernEnglish (Inglês Moderno). $O$ inglês antigo é impossível de ser lido hoje em dia sem a ajuda de um profissional. O Middle English já é mais parecido com o que estamos acostumados ultimamente, como nessa passagem do livro "The Cunteburry Tales" (os contos de cantuária): "Whilom, as olde stories tellen us, Ther was a duc that highte Theseus: Of Atthenes he was lord and governour, And in his tymeswich a conquerour That gretter was ther noon under the sonne". (VIZIOLI in CHAUCER, 1988, p. 7-8).

Repare que oração existencial "Ther was a duc that highte Theseus" já é um tanto parecida com a que temos nos dias atuais que seria "there was". A distância já não é tão grande como quando comparamos o inglês dos dias de hoje com o inglês antigo, o inglês médio já tem algumas semelhanças.

Por fim, muitas influências foram desencadeando mudanças no inglês e, por consequência, nas orações existenciais ao longo da história. As culturas que participaram do processo de formação do inglês fizeram com que a língua inglesa fosse criando afinidade com várias outras línguas e, assim, virando uma língua global. A influência latina explica alguma semelhança que essa língua chega a ter com o português.

\subsection{Falando sobre as estruturas das existenciais}

As construções existenciais têm uma morfossintaxe um pouco diferente de outras sentenças, mas denotam a existência de algo ou alguém em um contexto. Elas são formadas da seguinte maneira:

(Expletivo) - (pro forma) -( cópula )- pivô - (coda) 
As formas foram colocadas em parênteses para mostrar que elas variam de uma língua para outra e somente o pivô está universalmente presente nas línguas. O pivô é uma frase nominal que vem imediatamente depois da cópula. Vejamos alguns exemplos no francês, inglês e português do Brasil:
a. II y a des livres sur la table.
Expl.. prof. copula pivô coda
b. There are some books on the table.
Prof. copula pivô coda
c. Tem alguns livros sobre a mesa.
Copula pivô coda

Como se pode perceber a partir desses exemplos, o francês possui a estrutura completa de uma sentença existencial, o inglês não tem o expletivo e o português não tem o expletivo e a proforma.

No português, é possível que a coda, elemento opcional na sentença, venha em posição inicial, o que não é comum no inglês:

$\begin{array}{lll}\text { No Brasil, } & \text { tem } & \text { muita poluição. } \\ \text { Coda } & \text { copula pivô }\end{array}$

No exemplo acima, ainda é possível trocar o verbo "ter" pelo verbo "haver". Porém, esse último está caindo em desuso, sendo empregado em contextos mais formais e, na maioria dos casos, na forma escrita da língua, tornando-se quase extinto na fala do português do Brasil. E, muitas vezes quando empregado, seja na fala ou na escrita, ele é muito frequentemente usado de maneira incorreta, de acordo com a gramática tradicional, que diz que o mesmo é impessoal. Não é muito difícil ouvirmos ou lermos frases como "sempre haverão pessoas com intuito de nos menosprezar" ou "ainda haverão fotos de passeios".

Em inglês, há a discussão sobre as sentenças locativas e as existenciais. Vejamos alguns exemplos abaixo que ilustram essa discussão:

a. There are the girls, in the room.

b. There are some girls in the room.

Há quem diga que a sentença em "a" é considerada agramatical, mas continuemos a análise. A primeira sentença é uma sentença locativa na qual "there" é usado, de fato, como advérbio locativo e "the girls" é restritivo, definido. O resto da frase "in the room" seria um locativo tópico, referindo-se ao já citado "there", ou vice-versa. No segundo exemplo, temos uma construção existencial. A partir daí, infere-se que as orações existenciais não podem ter como pivô um substantivo definido.

Assim, percebe-se que o inglês apresenta a estrutura um pouco mais completa do que no português, mas, veremos a seguir, que os aprendizes de língua inglesa tentam padronizar a língua estrangeira de acordo com a língua materna deles. 


\section{A interferência do português (língua materna) na aprendizagem da língua inglesa}

Tendo visto a história das orações existenciais no português e inglês e como elas são formadas nas duas línguas, damos continuidade ao trabalho falando sobre interferência que é o que a acontece quando, ao invés de utilizarem "there + to be", os alunos utilizam "have" para indicar a existência de alguma coisa na LE. Assim, aqui falaremos sobre o inglês como língua franca, sobre como o português interfere na língua estrangeira e como a tradução pode influenciar de forma negativa ou positiva a aprendizagem da LE.

\subsection{Inglês como língua franca}

Lingua franca é uma expressão que vem do latim que significa língua de contato, isto é, a língua que resulta do contato e comunicação de membros de grupos que falam línguas diferentes para o comércio internacional e outras interações mais extensas. De acordo com Harmer (2004), o inglês tornou-se língua franca, mesmo não sendo a língua mais utilizada pela maioria dos falantes em todo o mundo.

A língua inglesa tem uma forte influência em várias partes do mundo, isso se deve ao notório poder econômico e cultural dos Estados Unidos, assim sendo, o inglês é, muitas vezes, utilizado tão bem quanto os falantes utilizam sua língua materna. Harmer (2004) diz que o inglês é uma das principais línguas de comunicação internacional assim como o latim foi na Europa durante a Idade Média e que mesmo pessoas que não são falantes conhecem palavras tais como bank, chocolate, computer, hamburger, hospital, hot dog, hotel, piano, radio, restaurant, taxi, telephone, television, university e walkman.

No Brasil, o inglês é ensinado em escola de ensino fundamental e médio. Em Brasília, há Centros de Línguas que ensinam língua inglesa de uma forma diferente das escolas regulares, e ainda há escolas de idiomas particulares espalhadas por todo o país com o objetivo de fazer com que mais e mais pessoas se tornem fluentes no uso dessa língua.

\subsection{A INTERFERÊNCIA DO PORTUGUÊS NA SEGUNDA LÍNGUA}

Quando alunos estão aprendendo uma língua estrangeira, já trazem consigo uma concepção de mundo, a qual eles querem colocar em prática na língua que estão aprendendo igual fazem na língua materna. Dessa maneira, eles tentam fazer relações da língua estrangeira com a língua mãe no momento da aprendizagem. Esse tipo de transferência é uma das maiores causas de erro que os estudantes cometem quando estão aprendendo uma língua estrangeira.

Falantes de duas línguas geralmente usam mais de uma língua para se comunicar, utilizando, dessa forma, a L1 e LE, ou seja, na interação com outro falante, uma língua é automaticamente ativada na falta de uma palavra em particular em outra língua, assim, o falante recorre de forma involuntária à L1 para procurar termos da LE em que a pessoa está se comunicando. Todo esse processo se dá como resultado da interferência da L1 e 
que, como já anteriormente citado, acaba resultando em erros.

A aquisição da língua alvo não é um processo simples de utilizar palavras da L1 dentro de frases da LE. Segundo Rinvolucri (2001), os professores devem saber que a língua materna e língua estrangeira estão presentes na mente do aluno e elas podem também estar presentes nas atividades de aprendizado. Se a língua materna for deixada de lado, há um grande risco da mente do aluno fechar para a parte criativa e prazerosa de se aprender uma segunda língua e é óbvio que alunos aprendem muito mais quando estão de fato mais interessados no assunto, sem contar que, com frequência, alunos usam a frase "How do you say ... in English" para completar sua comunicação. Assim, vêse que não tem como fugir do papel que a língua materna tem no processo ensinoaprendizagem de uma segunda língua.

Quando os alunos empregam a pergunta "how do you say ... in English", percebese duas coisas importantes: a primeira delas é que recorremos à L1 automaticamente sempre que não conseguimos nos expressar em inglês, dessa forma, a tradução é mesmo uma saída que nossa mente utiliza na aprendizagem de uma segunda língua. De acordo com a fala de Faleiros (2004) mesmo que os professores não queiram, os alunos utilizam a tradução mentalmente ou entre eles. Ele acrescenta que a tradução não deve ser usada de qualquer forma, porque ela pode impedir que o aluno se desenvolva na língua estrangeira que ele está adquirindo. A segunda coisa importante que a pergunta acima nos remete é que compreendemos o léxico de uma língua intuitivamente, assim, haverá expressões que serão lembradas e não compreendidas e não deveremos aplicar tradução de palavra por palavra.

A tradução palavra por palavra pode ter vários efeitos negativos na aprendizagem da segunda língua, então Lewis (1997) sugere que a identificação seja não em palavras, mas em blocos de enunciados, já que encontrar um equivalente da L1 na LE é quase impossível. Jacobs (1999) acrescenta que:

\footnotetext{
uso de português falado em inglês é um recurso muito comum no início do aprendizado porque o estudante não domina uma quantidade suficiente de termos e expressões em inglês. Com o progresso nos estudos, a tendência é parar de traduzir ao pé da letra(...). O Portuguese in English, entretanto, torna-se o grande vilão do aprendizado porque muitas vezes ele não é corrigido nem pelos ouvintes nem pelos professores, acomodados pela facilidade de compreensão. Com um estrangeiro, esse tipo de diálogo é impossível, pois Portuguese in English não é inglês.
}

Ainda de acordo com Lewis (1997), a tradução de blocos de enunciados é mais vantajosa gramaticalmente e o conteúdo do enunciado será transmitido de forma mais satisfatória.

\subsection{Transferência: aspectos positivos e negativos}

A transferência é o processo de empréstimos de termos lexicais e gramaticais da LM para LE, quando o aluno faz uso desse tipo de técnica, ele está pondo em prática uma estratégia de aprendizagem: "O uso da língua materna pelo aluno durante o processo ensino-aprendizagem é quase inevitável. Esse uso pode ser uma ferramenta útil e não um obstáculo que leva o aluno a cometer erros, ou que o desvia de um progresso na língua 
estrangeira" (FALEIROS, 2004, p. 48). A transferência se dá quando os itens da LM e da LE são parecidos e os aprendizes da LE os transferem. Jacobs (2003) fala sobre os alunos traduzirem mentalmente antes de responderem qualquer coisa e diz que os alunos afirmam que é inevitável não traduzir. De acordo com Jacobs (2003), isso significa que o aluno não quer evitar, porque quando alguém pergunta se ele está bem, ele responde automaticamente, não fica pensando na resposta. O autor mencionado acima ainda acrescenta que essa tradução faz parte de um medo, de uma insegurança que o aluno tem de errar ou fracassar e os outros o verem como ignorantes. Enfim, essa transferência é inevitável, uma vez que o estudante não pode apagar o conhecimento prévio que ele tem.

O que o aluno aprendeu antes pode afetar de forma positiva ou negativa a aprendizagem seguinte, isso vai depender se o que ele aprendeu anteriormente se encaixa ou se opõe com o que ele virá a aprender. De acordo com Selinker (1972), quanto maior for a diferença entre duas línguas, menor será a possibilidade de empréstimos entre a LM e a LE, ou seja, a semelhança entre duas línguas pode facilitar ou não a sua aprendizagem, sendo assim, a transferência entre uma língua e outra pode ser positiva ou negativa.

Corder (1981) defende que a transferência positiva quando ela auxilia a aprendizagem da LE, isto é, quando uma estrutura, por exemplo, é correspondente na LM e na LE. De acordo com Lewis (1997), O aluno que está estudando a LE forma um léxico na sua cabeça e uma interpretação da estrutura da LE a qual ele chama de intergramática. Esse conhecimento é adquirido através de músicas, aulas, leituras do idioma e analogamente a LM. Dessa maneira, é positivo fazer uso desta tendência, visto que algumas regras da língua materna do aluno também são aplicadas na língua estrangeira estudada. Krashen (1982) diz que "a transferência positiva refere-se ao uso automático da estrutura da língua materna no desempenho da língua estrangeira, quando a estrutura em ambas as línguas são a mesma, resultando em declarações corretas". Assim, algumas estruturas na língua alvo são, de fato, correspondentes às da língua nativa do aluno e aí a transferência desempenha um papel importante na prática da LE. No caso do inglês e português, muitas palavras são parecidas e realmente significam a mesma coisa, isso ocorre mais frequentemente do que os falsos cognatos, por exemplo.

A transferência negativa, também chamada de interferência ou estudo dos erros, foi definida por Selinker (1972) como um sistema linguístico separado evidenciado quando um aprendiz de uma LE tenta se expressar na língua que está estudando, sendo influenciado pelos padrões da LM na aquisição dos padrões da língua alvo. A interlíngua se diferencia sistematicamente da língua materna e da língua estrangeira, tendo suas próprias regras:

Uma interlíngua pode ser linguisticamente descrita como os dados produzidos por falantes preocupados em reproduzir uma língua estrangeira padrão, isto é, tanto seus erros como acertos. Tal comportamento é altamente estruturado. A partir dos trabalhos em transferência linguística, parece impossível não reconhecer a existência de uma interlíngua e ela deve ser tratada como um sistema, não como um conjunto isolado de erros. (SELINKER, 1969) 
A interlíngua vai ajudar a mostrar o desenvolvimento do aluno ao longo do processo, mostrando avanços, retrocessos, variações e até fossilizações.

De acordo com Selinker (1972), um dos pontos mais importantes na interlíngua é a fossilização. Ele diz que esse é um processo pelo qual a interlíngua pode passar, são "formas da LM que são erroneamente identificadas como equivalentes da LE, e assim transferidas ficam estabilizadas eventualmente se fossilizam, mas pensa-se que tal processo seja irreversível." O autor acima descreve que há cinco processos centrais na fossilização, são eles: processo de transferência linguística, supergeneralização do material linguístico da língua alvo, transferência de instrução, estratégias de comunicação na segunda língua e estratégia de aprendizagem da L2.

a. Processo de transferência linguística: o componente que foi fossilizado resulta da língua materna.

b. Supergeneralização do material linguístico da língua alvo: é quando o aprendiz generaliza as regras da língua alvo, não levando em conta as exceções.

c. Transferência de instrução: esse processo ocorre quando o aprendiz aplica regras aprendidas em livros e com instrutores em contextos que não cabem a regra e esses erros acabam fossilizados.

d. Estratégia de comunicação: é o processo usado pelo aprendiz para resolver problemas de comunicação quando a sua interlíngua não é suficiente para a tarefa. Quando ele tenta se comunicar e não tem conteúdo linguístico suficiente para passar a mensagem, ele usa essa estratégia.

e. Estratégia de aprendizagem: é usada de forma consciente pelo aprendiz para dominar a língua alvo, pode ser o uso de flshcards, de livros didáticos ou qualquer outro tipo de material que vai mediar essa aprendizagem.

Dessa maneira, vemos que a fossilização se apresenta como um estado semipermante, é como que se houvesse um tipo de interrupção do desenvolvimento. Para outros autores, ela é um estágio mais demorado que os outros e pode ser identificada e superada.

\section{Sobre os procedimentos da pesquisa}

O uso de "have" ao invés de "there + to be" é um assunto que está sempre sendo discutido entre professores de inglês. Eles escutam o tempo inteiro a troca que os alunos fazem de um pelo outro em redações, apresentações e em falas de todos os dias em sala de aula.

Pit Corder (1981) explica que os erros que os estudantes cometiam em aulas de LE eram analisados como desvio da norma ou dificuldade de aprendizagem. Corder (1973) é o primeiro estudioso a defender que o erro era uma coisa de grande importância para o aluno e para o professor, pois isso permite com que hipóteses sobre a natureza da língua estrangeira sejam comprovadas. Os erros também permitem aos professores perceberem as áreas que os alunos têm mais dificuldade e também auxiliam na produção de livro didáticos para o ensino da LE.

Dessa maneira, o erro toma um valioso espaço no estudo de aquisição de segunda 
língua ou língua estrangeira. Nesta sessão, será discutido o que motiva os alunos a fazerem esse tipo de troca nessas estruturas, o porquê esse tipo de troca é feito apenas em alguns contextos e em outros não, a razão pela qual alunos em um mesmo nível, da mesma turma, fazem o uso da variação e outros mantêm a forma correta da língua. Falaremos também sobre uma nova estrutura que começa a tomar espaço tanto no ensino de inglês como no uso do idioma, a estrutura "it has".

\subsection{Metodologia}

Esta pesquisa será descrita através do método qualitativo do tipo etnográfico, uma vez que ela parte da observação de dados de sentenças existenciais obtidas em duas turmas de LE durante um semestre, sendo a LE a língua inglesa. Esse tipo de pesquisa foi originalmente desenvolvida pela antropologia, com o objetivo de relatar comportamentos e padrões culturais de um determinado grupo social. Sendo assim, De acordo com Watson-Gegeo (1988), a pesquisa de cunho etnográfica define-sea partir do estudo de como as pessoas se comportam em um contexto de interação social específico, focando na interpretação cultural desse comportamento. Dessa forma, o pesquisador, nesse paradigma, observa sistematicamente, intensivamente e detalhadamente $o$ comportamento das pessoas em um contexto.

Os alunos foram observados em seu contexto de sala de aula, na forma como interagiam com colegas de sala e professores e deste ponto foram coletadas frases existenciais. Em um segundo momento, alguns alunos foram convidados a descrever figuras e foram gravados as descrevendo. O tipo de linguagem que será considerada nessa pesquisa é a oral.

\subsubsection{O contexto, os sujeitos e a geração de dados}

A pesquisa foi iniciada em um dos Centro Interescolar de Línguas (escola pública especializada no ensino de línguas estrangeiras), localizado no Distrito Federal, com alunos que já estudam na escola por dois e três anos. A turma que está na escola há dois anos tinha como conteúdo mínimo o uso de there is/ are para descrição de substantivos contáveis e incontáveis e para a descrição da cidade em que eles vivem. Já a turma que estuda inglês há três anos na escola não tinha esse assunto como conteúdo mínimo desse semestre, porém já tinham estudado antes.

A primeira parte da pesquisa foi de observação e coleta de dados de todos os alunos que estavam na turma. Na segunda parte da pesquisa, foram selecionados quatro alunos de cada turma e estes tinham que descrever uma figura, porém o professor não especificou qual o tipo de estrutura os alunos teriam que utilizar nessa descrição. A primeira parte foi um tanto difícil para a coleta de dados principalmente na turma de básico 4, porque os alunos se comunicam a maior parte do tempo em português, mas alguns alunos, quando vão se comunicar com o professor, utilizam inglês, mas não são todos os alunos. A turma de específico 6 era mais disciplinada com relação ao uso da língua alvo em sala, porém os dados foram coletados quando os alunos estavam compartilhando histórias com seus colegas e ficou um pouco complicado para o 
pesquisador compreender o contexto daquela sentença.

Os alunos do básico 4 têm entre 13 e 14 anos e os alunos do específico 6 têm entre 17 e 23 anos. O básico 4 faz parte do curso regular do Centro de Línguas e tem 5 anos de duração e o específico 6 é um curso expresso e tem 3 anos de duração, o aluno que termina esse curso sai com o nível pré-intermediário completo.

\subsubsection{As figuras usadas para a descrção}

Os alunos foram convidados individualmente para descrever as figuras, eles foram avisados em português que deveriam descrevê-las, alguns perguntavam o que deveriam usar para a descrição, mas os alunos foram instruídos a utilizarem o que viesse à cabeça deles no momento.

A figura 1 (olhar anexos, figura 1) é a figura de uma família em uma biblioteca onde há livros e alguns objetos sob a mesa, essa figura foi utilizada com o grupo de especifico 6. Já a figura 2 (Olhar anexos, figura 2) é uma geladeira com vários itens contáveis e incontáveis. Os alunos também receberam as devidas instruções do que deveriam fazer em português. A figura 2 foi utilizada duas vezes no semestre: nesse primeiro momento e no final do semestre para a prova oral.

\section{Análise dos dados}

No início, foram colhidos dados de falas espontâneas dos alunos quando conversavam com colegas da turma ou até mesmo com professor. Sobre esse tipo de coleta SPRADLEY (1980, p.67) comenta que deve-se anotar as mesmas palavras que os participantes usaram ao invés de parafraseá-las. Por isso, erros gramaticais em língua inglesa serão encontrados ao logo da descrição da pesquisa com o objetivo de utilizar as mesmas palavras que os alunos usaram.

Na turma de básico (turma que está há dois anos na escola), surgiram sentenças feitas em atividades orais tais como:

(1) Teacher, have test today?

(2) Have water?

(3) Have 18 students in class.

(4) Have bakery next to café.

O dado (1) foi gerado por uma aluna que queria confirmar se haveria teste naquele dia. $O$ dado (2) surgiu a partir da necessidade do aluno em saber se tinha água nos bebedouros da escola devido ao racionamento que tem ocorrido em Brasília. Na preparação para um jogo, o professor precisava saber quantos alunos havia na turma e, na intenção de ajudar, o aluno contou e proferiu o dado (3). O dado (4) é um dado muito interessante, pois surgiu em uma prova oral na qual os alunos teriam que descrever onde estavam os lugares da cidade e todos os alunos da turma utilizaram "there to be" para fazer tal coisa, exceto esse aluno que havia faltado algumas aulas na qual o conteúdo tinha sido ministrado. Antes do conteúdo "there to be" ter sido ministrado, não houve dados com tal estrutura. 
Após a ministração do conteúdo, houve inúmeros exemplos de frases com "there to be", porém essas frases eram proferidas apenas nos contextos que eles aprenderam, são eles: descrição dos lugares das cidades e dos substantivos contáveis e incontáveis.

$\mathrm{Na}$ turma de específico, como já dito anteriormente, não havia "there to be" como conteúdo mínimo para esse semestre, mas já haviam estudado em semestres anteriores. Quando o professor pedia para que os alunos inteagissem com colegas em pares ou em trios sobre diversos assuntos, surgiam as sentenças com "have" ao invés de "there to be" e sentenças com "there to be":

(5) (...) Had a hole on the street.

(6) Have this boy that I don't like(...).

(7) In the story there is a man and a dog (...).

(8) There is these shoes that I love (...).

(9) (...)Have four peoples in my house.

A sentença (5) surgiu quando um dos alunos da turma foi contar como ele havia caído da moto, ele disse que havia um buraco na rua e ele passou com a moto no buraco e caiu. Um dos temas trabalhados durante o semestre foi "pet peeves" que são coisas que nos irritam, uma aluna (6) mencionou esse garoto da universidade com quem ela não tem um bom relacionamento. Os alunos leram um conto esse semestre e tiveram que compartilhar a história do conto deles e a interpretação com o colega que leu um conto diferente do dele e na sentença (7), o aluno mencionou os personagens da história. A número (8) surgiu a partir de uma discussão sobre qual era uma peça de roupa, calçado ou acessório em geral que os alunos tinham e que era de valor especial para eles. E, por último, a sentença (9) apareceu quando os alunos discutiam sobre a formatura na qual eles só ganharão três convites e se precisarem de mais algum, eles terão que comprar convite individual.

$\mathrm{Na}$ segunda parte da geração de dados, o professor mostrou figuras aos alunos e estes deveriam descrevê-las da forma como achassem melhor. No básico 4 , as seguintes falas surgiram entre os quatro alunos que foram convidados a descrever essa figura (ver figura $2 \mathrm{em}$ anexos):

(10) "In this picture, have a fish, a soup, a chicken, a coke, a banana and a egg"

(11) "there is a fish, there is a chicken, there is a ice cream, there is a soup, there is a watermelon, there is a tomatoes."

(12) "There is a fish, there is a pizza, there is a chicken, there is a lettuce, there is carrots, there is tomatoes and there are bananas"

(13) "There is some ice cream, there are some soup, there are a pizza, there are some coke, there are some bananas."

$\mathrm{Na}$ turma de E6, eles tinham que descrever uma outra figura (figura 1, ver em anexos), então surgiram as seguintes orações:

(14) "So in this Picture I can see there's a Family, there is a little kid, a busy woman 
and a father. He looks like he's not taking care of his son, he's just working and look like his parents... the kid's parents they look like they are not taking care of him (...) well, they looks like they are in the kitchen, they are taking a breakfast."

(15) "There are two persons and one children, have a lot of books. One table, have some pencils, have flowers in the window."

(16) "There is a family: a dad, a mom and a baby. But they don't have attention with the baby and they are having a breakfast, maybe, but they are doing other things. They have a lot of books in the shelf. And maybe they have a very good job, both of them and they look tired, so stressed.

(17) "one children, mother and father. Father at work, mother in the cell phone and children eat and home have books and the peoples stays in a table."

O que leva os alunos a cometerem esse tipo de erro? Esses erros já estão fossilizados na língua desses falantes? Qual seria a solução que o professor deveria usar diante desse constante desvio da língua alvo? Essas e outras perguntas serão respondidas na nossa análise na próxima sessão.

\subsection{Resultados da pesquisa}

A partir dos dados acima relatados, evidencia-se que os alunos estão utilizando um padrão na interlíngua e estão tentando adequar a língua inglesa a sua língua mãe, dessa forma, eliminando a proforma e deixando apenas a copula assim como é no português e como já foi discutido acima na sessão 1 deste artigo.

De acordo com Selinker (1972), todos nós temos uma estrutura psicológica latente e quando começamos a estudar uma língua estrangeira quando adultos, ativamos essa estrutura, diferentemente de quando estamos aprendendo nossa língua materna. Quando estamos adquirindo a língua materna, ainda segundo o autor acima citado, ativamos a estrutura latente da linguagem. Um dos motivos pela fossilização dos erros é a transferência linguística, a qual, também já discutida acima, pode ser positiva ou negativa. No caso dos alunos desse Centro de Línguas, essa transferência tem sido negativa nas orações existenciais.

Conforme Corder (1973), a interlíngua pode ser dividida em quatro fases: présistema (os alunos têm uma ideia meio vaga do que é a estrutura da língua), emergente (quando os alunos estão evoluindo na produção linguística e começam a internalizar alguns comandos, porém ainda cometem muitos erros e não conseguem os corrigir), sistemática (nessa fase, eles já conseguem corrigir erros caso alguém os aponte, as regras aqui ainda não estão bem definidas) e estabilização ou pós-sistemática (nesse momento, os alunos já conseguem se auto corrigir). Ao que se pode perceber, os alunos do básico 4 e alguns dos entrevistados do específico 6 encontram-se no estágio emergente e uma parte dos alunos do específico 6 encontram-se na fase sistemática.

Antes da estrutura das orações existenciais no inglês terem sido apresentadas aos aprendizes do básico 4 não houve dados de sentenças existenciais com a estrutura "there to be" e depois que eles foram expostos a essa estrutura, apareceram inúmeros exemplos, porém apenas em contextos restritos: para descrever a cidade e os 
substantivos contáveis e não contáveis.

É interessante analisar que o aluno faltoso usou a sentença "have bakery next to café" quando todos os outros alunos da turma utilizaram "there is/are" no mesmo exercício. Outro fato pertinente foi que, na prova oral de final de semestre, o professor utilizou a mesma figura utilizada na pesquisa e a turma inteira utilizou there is/ are (mesmo cometendo erros de singular e plural) e o mesmo aluno continuou utilizando a estrutura com "have" para indicar a existência de substantivos contáveis e não contáveis na geladeira. Isso nos prova que o input é uma coisa determinante no ensino da LE, uma vez que o aluno que não foi exposto a quantidade e a qualidade de input suficientes, ele não conseguiu assimilar e produzir o que era esperado dele na língua alvo, pelo contrário, o uso de "have" parece estar fossilizado em sua fala. Segundo Krashen (1987 apud Schutz, 2006), a aquisição de uma língua não acontece de uma hora para outra, mas sim de maneira gradual, dessa maneira, algumas estruturas da língua, tais como plural regular e entonação, são internalizadas mais rapidamente e outras, como flexão verbal e concordância, são adquiridas mais tardiamente. Porém, para que o aprendiz evolua na língua, indo de um estágio a outro, é preciso que o input esteja em um nível maior do que o estágio em que o aprendiz está.

$\mathrm{Na}$ descrição de figura (17), o aluno também parece estar no estágio emergente, mesmo estando para concluir o pré-intermediário, uma vez que nas sentenças usadas faltam verbos e ela usa "have" ao invés de "there is/ are" e essa estrutura também parece estar fossilizada na língua do aprendiz. Porém, não adianta apenas encher o aluno com input descontextualizado, é preciso que esse input seja algo que o aluno consiga compreender, posto que Krashen afirma que apenas ser exposto frequentemente a determinadas formas linguísticas não o ajudará a internalizá-las mais rapidamente, Krashen (1982, apud SCHUTZ, 2006) afirma que:

\footnotetext{
O aluno só adquirirá o que estiver no ponto certo de seu desenvolvimento maturacional, não importando a freqüência com que ele é exposto, e nem o grau de dificuldade envolvido. Assim, as estruturas que estejam além de seu desenvolvimento serão apenas memorizadas, sem, contudo, serem integradas, o que significa uma não capacidade desse aluno de usá-las efetivamente.
}

Schutz (2006) dá algumas sugestões para que os aprendizes ultrapassem essa fase de interlíngua. Ele sugere que quanto mais o aluno for exposto a LE e quanto mais rápido for o processo de assimilação menor será o tempo de interlíngua e menor será a possibilidade de fossilização de estruturas, a autenticidade e qualidade do input também têm que ser de um grau elevado. Ele afirma também que o sucesso na língua alvo depende do tamanho do grupo e do tipo de aprendiz, isso quer dizer que grupos grandes propicia o uso interlíngua e aprendizes mais extrovertidos têm mais sucesso na aprendizagem de uma LE, pois esses alunos sempre estimulam mais a parte oral.

Por fim, percebe-se que o uso de transferência na aprendizagem de uma segunda língua vai acontecer independente da vontade do professor. Essa transferência, por outro lado, pode ser positiva ou negativa. Quando negativa, a chamam de interferência, essa é uma fase que o aprendiz de uma língua estrangeira vai passar de qualquer forma e é a fase que a maioria dos alunos participantes desta pesquisa estão passando. A interlíngua 
para ser superada precisa de um pouco mais de dedicação por parte do aprendiz e é importante que o professor analise a quantidade e qualidade do input que ele está usando com esse aluno para que formas fossilizadas, tais como as dos dados da pesquisa, desapareçam da fala do aluno e sejam substituídas pela correta utilizada na LE.

\section{Considerações Finais}

Neste artigo, mostrou-se o resultado de uma pesquisa feita com alunos do final do básico e do final do pré-intermediário na qual mostra um erro de fossilização na fala dos mesmos. Fossilização diz respeito a um fenômeno linguístico no qual é comum o aparecimento de estruturas linguísticas que não pertencem à língua estrangeira que está sendo aprendida.

Considerando a aprendizagem formal de segunda língua, alguns autores defendem que a principal causa de erros é a pobreza de dados em sala de aula, o input. Outros culpados são o material didático e a maturidade do aluno, muitas vezes o aprendiz não está preparado para receber determinada estrutura da língua.

Uma ferramenta importante que dá suporte ao aluno para superar a fase de interlíngua e os erros fossilizados é o feedback e os professores de língua estrangeira devem fazer o uso dele constantemente. O feedback é usado para informar ao aluno se seu comportamento no idioma está correto ou se precisa melhorar e permite que o professor provoque o aluno a pensar, fazendo com que os aprendizes sejam capazes de identificar seus erros e mudem de estágio, dessa forma, evoluindo na língua. Sem o feedback, os alunos ficam parados, sem muito desenvolvimento na LE.

As contribuições deste artigo podem auxiliar o professor no entendimento de que o aluno faz transferências da sua língua materna todo o tempo e essas podem ser positivas ou negativas. Quando a transferência de estruturas é negativa, tem que se trabalhar melhor com a qualidade do input que está sendo usado, bem como analisar se o aluno já está preparado a receber determinada estrutura. Por fim, no ensino formal, o professor tem que investir constantemente no feedback para que seu aluno se desenvolva na língua. Em resumo: espera-se que este trabalho colabore com o ensino/aprendizagem de língua estrangeira por falantes de língua portuguesa. 


\section{Referências bibliográficas}

ALMEIDA FILHO, José Carlos Paes de. (2007). Lingüística Aplicada, ensino de línguas e comunicação. Campinas: Pontes Editores. P. $64-67$

CORDER S. P. 'Error analysis and interlanguage.' Oxford: Oxford University Press, 1981.

CORDER S.P Indiosyncretic dialetic and error analysis. Em: International Review in Applied Linguistics. Ingraterra: Oxford University Press, 1971.

FALEIROS, M. H. V. A influência de atividades orais na produção oral e escrita de alunos de inglês como L2. 2004. 131 f. Dissertação (Mestrado em Ciências e Práticas Educativas). Universidade de Franca, Franca, 2004.

HARMER, J. The world of English. In: . The practice of English language teaching.

3. ed. Harlow: Longmam, 2004. p. 1-11.

KAYNE, R. S. Expletives, Datives, and the Tension between Morphology and Syntax. In: BIBERAUER, T. (Ed.). The Limits of Syntactic Variation, John Benjamins, Amsterdam, p. 170-217, 2006.

JACOBS, M. Como "não" aprender inglês: erros comuns do aluno brasileiro. São Paulo: Câmara Brasileira do Livro. 1999. P. 129

LEWIS, M. The Role of L1 in the Lexical Approach. In: Implementing the lexical approach: putting theory into practice. Hove: LTP, 1997. cap. 4, p. 55-70.

LYONS, J. Introduction to theoretical linguistics. Cambridge: Cambridge University Press, 1968.

MATTOS E SILVA, R. V. Variação e mudança no português arcaico: TER ou HAVER em estruturas de posse. In: PEREIRA, C. C.; PEREIRA, P. R. D. (Org.). Miscelânea in memorian de Celso F. da Cunha. Rio de Janeiro: Nova Fronteira, 1995, p. 285-298.

POULISSE, N.; BONGAERTS, T. First Language use in second language production. Applied Linguistics, Oxford, v.15, n.1, p. 33-57, Março. 1994

RIBEIRO, I. M. O. A formação dos tempos compostos: a evolução histórica das formas ter, haver e ser. In: ROBERTS I.; KATO, M. A. (Org.). Português brasileiro: uma viagem diacrônica, Campinas, Editora UNICAMP, 1996, p.343-386.

SELINKER, LARRY (1972). 'Interlanguage.' IRAL 10, 209-231, 1972.

SHÜTZ, Ricardo. Comunicative Approach-Abordagem Comunicativa: english made in 
Brazil. Disponível em Acesso em 20 de junho de 2017.

SPRADLEY, J. Participant observation. Fort Worth: Harcourt Brace College Publishers, 1980.

VIZIOLI, P. Apresentação e Notas. In: CHAUCER, G. Os contos de Cantuária. Tradução direta do Médio Inglês e notas de Paulo Vizioli. T. A. Queiroz, Editor. São Paulo: 1988.

WATSON-GEGEO, K.A. Ethnography in ESL: defining the Essentials. TESOL Quarterly, 1988, p. 575-592. 


\section{Anexos}

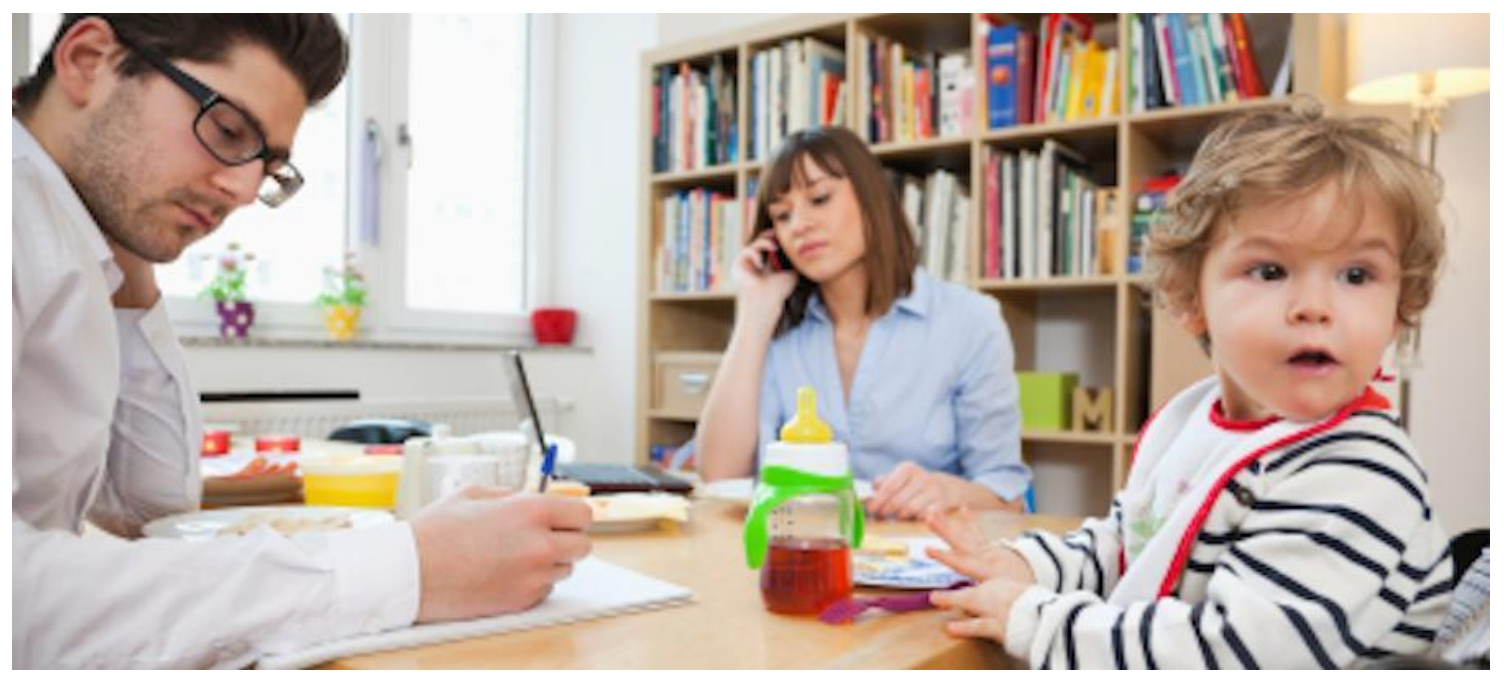

Figura 1

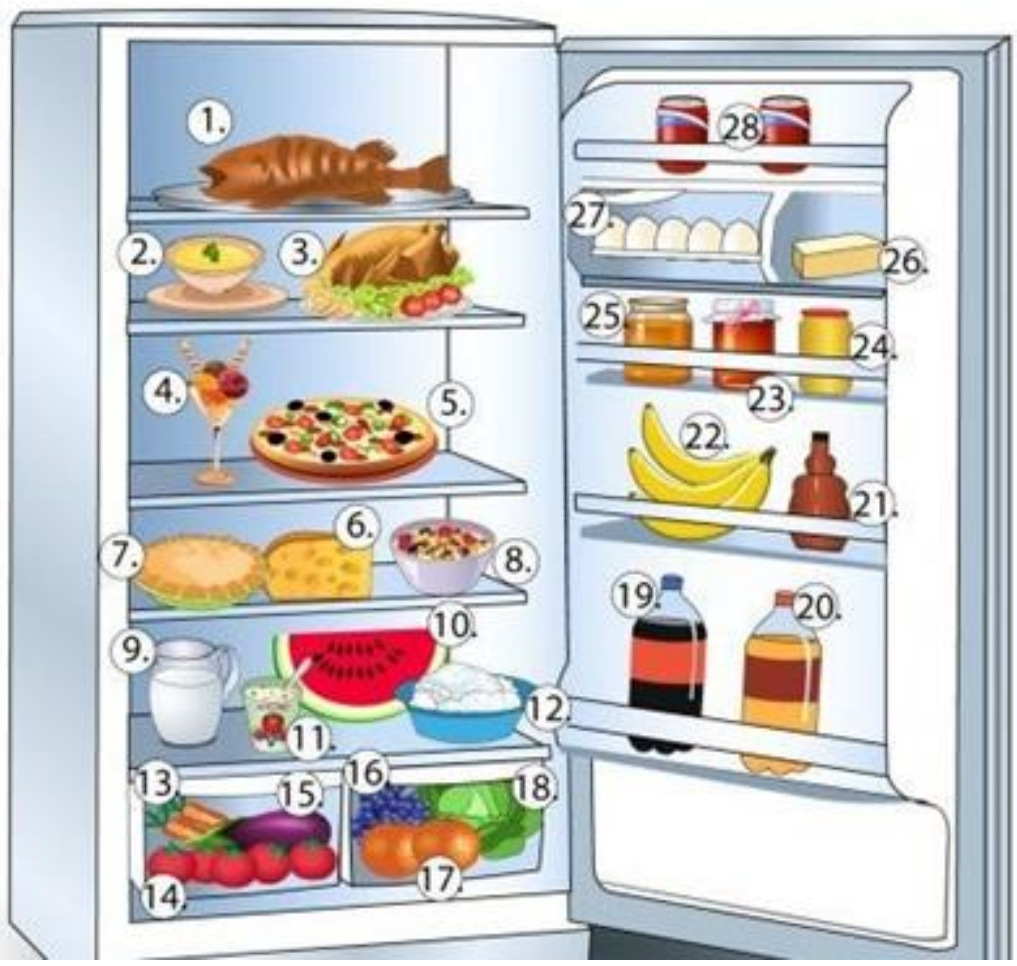

Figura 2 